analecta polit. | Vol. 10 | No. 18 | PP. 178-204

| enero-junio | 2020 | ISSN-e: 2390-0067 (en línea) | Medellín-Colombia

http://dx.doi.org/10.18566/apolit.v10n18.a09

\title{
¿La delegación permanente de funciones jurisdiccionales a las superintendencias colombianas vulnera los derechos humanos?*
}

Cómo citar

este artículo en APA:

Sanín Gómez, J. E.

(2020). ¿La delegación

permanente

de funciones

jurisdiccionales a las

superintendencias

colombianas vulnera

los derechos humanos?

Analecta Política, 10(18),

178-204.
Fecha de recepción:
Does the permanent delegation of jurisdictional functions to the Colombian superintendencies violate human rights?

\section{JUAN ESTEBAN SANÍN GÓMEZ}

Magíster en Derecho con énfasis en Tributación Ignacio Sanín Bernal y Cia. Abogados, Colombia

Correo electrónico: juan.sanin@isanin.com.co
}

Producto adscrito al grupo de investigaciones en Derecho GRID del" Proyecto General". Radicado 374C-11/18-36. 


\section{Resumen}

En el presente artículo se estudia el fenómeno de la delegación de funciones jurisdiccionales a las superintendencias colombianas y la eventual transgresión que ello pueda tener en materia de derechos humanos, por cuanto podría verse comprometida la independencia judicial como un valor inescindible del concepto de justicia. Para ello se analiza la institución de la separación de poderes, se analiza el proceso jurídico que vivió Colombia para segregar estas funciones de la rama judicial y se analiza este fenómeno a la luz del control de convencionalidad que deben hacer los jueces en cumplimiento de los tratados internacionales de derechos humanos. La conclusión de este estudio es que la delegación de funciones jurisdiccionales en las superintendencias colombianas vulnera el derecho fundamental y humano a ser juzgado por un operador judicial independiente.

Palabras clave: separación de poderes, derechos humanos, superintendencia, independencia, imparcialidad.

\section{Abstract}

This article studies the phenomenon of the delegation of jurisdictional functions to the Colombian superintendencies and the possible transgression that this may have in terms of human rights, since judicial independence could be compromised as an essential value of the concept of justice. To do this, the institution of the separation of powers is analyzed, as well as the legal process that Colombia lived to separate these functions from the judicial branch. In sum, this phenomenon is examined in light of the control of conventionality that the judges must do in compliance with international human rights treaties. The conclusion of this study is that the delegation of jurisdictional functions in the Colombian superintendencies violates the fundamental and human right to be tried by an independent judicial operator.

Keywords: separation of powers, human rights, superintendency, independence, impartiality. 


\section{Introducción}

Colombia está celebrando el bicentenario de su independencia. Tras lograr deshacerse del absolutismo monárquico (que, como cualquier régimen absolutista concentraba despóticamente en sí los poderes propios del Estado), nuestro país ha buscado el equilibrio de poderes en una docena de constituciones que "se han hecho o se han deshecho al galope de nueve guerras civiles" ${ }^{1}$ hasta llegar a la Carta de 1991. Tal como se desprende del preámbulo de la Constitución Política, la justicia es uno de "los valores fundantes del Estado colombiano" (Sentencia SP4198-2019/49222 de octubre 2 de 2019). Igualmente, nuestro ordenamiento constitucional (Constitución Política, art. 2) establece como fines esenciales del Estado asegurar la vigencia de un orden justo. Esto coincide con lo que indica Rawls (1999) cuando manifiesta que "la justicia es la primera virtud de las instituciones sociales, así como lo es la verdad para los sistemas de pensamiento” (p. 3).

El actual régimen constitucional consagra, tanto en su parte dogmática como en su parte orgánica, dos estipulaciones que serán objeto de análisis en este estudio y que podrían romper con el postulado de separación de poderes, así como vulnerar los derechos humanos reconocidos por Colombia en tratados internacionales. Se trata, pues, por una parte, del enunciado respecto de que Colombia, siendo un país soberano, respetará los principios del derecho internacional y se orientará hacia la integración de América Latina y el Caribe (Constitución Política, art. 9) y, por la otra, del enunciado que indica que, de forma excepcional, la ley podrá atribuir funciones jurisdiccionales en materias precisas a determinadas autoridades administrativas (art. 116).

El propósito de este artículo es revisar la estructura judicial colombiana relacionada con la delegación permanente de funciones judiciales a entidades administrativas para determinar si, a la luz de los tratados internacionales de derechos humanos y de la teoría general del Estado, esta delegación permanente es inaceptable.

1 Véase Lemos (1998, p. 12-20), 


\section{La separación de poderes y el sistema de pesos y contrapesos como pilar fundamental del Estado constitucional}

De la Revolución francesa, ${ }^{2}$ que dio fin al sistema absolutista caracterizado por que el rey concentraba todas las funciones del Estado, ${ }^{3}$ heredamos la separación de poderes ${ }^{4}$ como principio político y pilar fundamental de los Estados modernos. Esta separación entre el poder ejecutivo, legislativo y judicial, que implica que cada función sea ejercida por fuerzas mecánicamente limitadas y representativas de los diferentes sectores sociales, ${ }^{5}$ no solo es un principio político rector del Estado moderno, sino que como garantía de los derechos - primero naturales y luego positivos- de los individuos ${ }^{6}$ hace parte fundamental de la Declaración de los Derechos del Hombre y del Ciudadano, que posteriormente inspiró la Declaración Universal de los Derechos Humanos y la Carta Internacional de Derechos Humanos de la cual Colombia es parte.

Este hilo de pensamiento crítico que nace con Aristóteles en la antigüedad (Solozábal, 1981) se consolida con Montesquieu en la Ilustración francesa y culmina su recorrido con el empirismo inglés de Locke, y así inspira la formación del Estado moderno. No obstante, ha tenido también grandes críticos dentro de los cuales se encuentran autores como Léon Duguit, Georg Jellinek, Moreau de Saint-Méry, Léon Cahen y Charles Seignobos, los cuales manifiestan que esta postura atenta contra el principio de unidad del Estado, desconoce la importancia de la exclusividad funcional y deniega la supremacía de la función legislativa sobre la ejecutiva y judicial (p. 227).

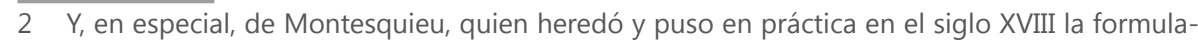
ción teórica y la tesis de esta separación delineada por Locke en su Segundo ensayo sobre el gobierno civil, que a su vez tomó prestado de La política, de Aristóteles (Salazar, 2006, p. 87; Concha, Hernández y Torres, s. f.).

3 De ahí la famosa frase de Luis XIV "L'Etat c'est moi" (el Estado soy yo).

4 Montesquieu plantea que la autoridad tiene tres funciones: "dictar leyes, ejecutar las resoluciones públicas y juzgar las causas y pleitos entre particulares" (Portland Public Schools, s. f.).

5 "Además, los poderes representarían a los diferentes sectores sociales, por lo que los actos de gobierno serían fruto de negociaciones: el monarca encabezaría al ejecutivo, los nobles y el pueblo integrarían las dos cámaras del parlamento y los jueces serían "la boca que pronuncia la ley: seres inanimados que no pueden regular ni su fuerza ni su severidad" (Salazar, 2006, p. 88).

6 Salazar (2006, p. 89), teniendo como punto de partida la teoría de la separación de poderes de Montesquieu, cita a Troper (1999) quien desarrolla la idea de que la Constitución es una máquina de "poder que frena el poder". 
De la separación de poderes emanan dos principios fundamentales característicos del Estado constitucional: el principio de legalidad y el principio de imparcialidad, ${ }^{7}$ los cuales, según Salazar (2006), son indispensables para garantizar la libertad. Dentro de estos principios, la imparcialidad judicial ${ }^{8}$ termina siendo la quintaesencia del Estado constitucional, pues se convierte en la garante de la legalidad. En palabras de McIlwain (1947), "la única institución esencial para defender el derecho siempre ha sido y todavía es un poder judicial honesto, hábil, preparado e independiente"(p.55).

Esta separación de poderes está claramente demarcada en el artículo $113^{9}$ de la Constitución Política en que se indica que existen tres ramas del poder público, integradas por órganos del Estado autónomos e independientes, cuyas funciones difieren entre sí y colaboran armónicamente para la realización de sus fines. Ahora bien, es importante aclarar que el mandato de colaboración armónica, cuya importancia resalta la Corte Constitucional en Sentencia de Tutela ${ }^{\circ}$ 502/92 de Corte Constitucional, 21 de agosto de 1992, no puede entenderse como un amparo de medidas que impliquen invasión competencial ni como una patente de corso para delegar indefinidamente funciones de una rama del poder público a otra. ${ }^{10}$

7 Según Salazar (2006, p.90), interpretando a Bovero (2000), "el principio de legalidad consiste en la distinción y subordinación de las funciones ejecutiva y judicial a la función legislativa; el principio de imparcialidad consiste en la separación e independencia del órgano judicial: tanto del órgano ejecutivo como del órgano legislativo. El primero confirma la supremacía de la Ley y el segundo garantiza su aplicación efectiva".

8 Mientras el principio de legalidad "se refiere a las funciones del Estado, el principio de imparcialidad se refiere a los órganos estatales que ejercen las diferentes funciones" (Salazar, 2006, p. 90).

9 "Son Ramas del Poder Público, la legislativa, la ejecutiva y la judicial. Además de los órganos que las integran existen otros, autónomos e independientes, para el cumplimiento de las demás funciones del Estado. Los diferentes órganos del Estado tienen funciones separadas pero colaboran armónicamente para la realización de sus fines" (Constitución Política, art. 113).

10 "El principio inveterado según el cual las tres ramas del poder público deben cooperar en la realización de los fines del Estado social de derecho, previsto además en el artículo 133 [sic] de la carta política, es uno de los pilares que suele invocar el legislador cuando regula la atribución de funciones jurisdiccionales a las entidades públicas. A partir de esta consideración, suele entenderse que, cuando un órgano administrativo es facultado para que administre justicia, está colaborando con la rama judicial encargada de esa función" (Bejarano, 2018, p. 38). 
Lejos de la concepción de Estado trazada por Weber ${ }^{11}$ o soñada por Nozick ${ }^{12}$ y de la real función de la división o separación de poderes, ${ }^{13}$ la evolución de las sociedades ha permitido vislumbrar la existencia de otros poderes públicos, tales como aquel de los entes de control, ${ }^{14}$ el banco central ${ }^{15}$ y los medios de comunicación (Ortega, 2019), o el electoral y el "moral o ciudadano". ${ }^{16}$ La importancia de la separación de estos, para los fines de este estudio, se restringirá a la separación clásica entre el poder ejecutivo, legislativo y judicial.

\section{La separación de poderes y el nuevo contrato social: una aproximación pragmática a la teoría de la justicia de Rawls}

Rawls (1999) presenta una concepción de la justicia que "generaliza y lleva a un mayor nivel de abstracción la teoría conocida del contrato social trazada por Locke, Rousseau y Kant" (p. 10). Su teoría sobre el contrato social no se basa en el acuerdo realizado por personas libres para acordar una cierta forma de gobierno, sino, por el contrario, el acuerdo sobre los principios de justicia que han de permear la estructura social. Para poder establecer esos principios de forma objetiva, Rawls hace el ejercicio de imaginar que las personas que los acuerdan se encuentran en una "posición original", cubiertas por un "velo de ignorancia" que les permite estar en un verdadero estado de equidad y les prohíbe saber qué lugar ocuparían en la sociedad, razón por la cual están desprovistas de cualquier

11 Weber (1919) sostiene que el fin del Estado es la preservación del monopolio de la violencia.

12 Nozick (1974) establece que un Estado mínimo, restringido simplemente a la resolución de controversias entre individuos, podría considerarse un Estado utópico.

13 Weber (2004) estableció que "el poder de mando puede ser debilitado, además [...] por la división especificada de poderes: distribución de poderes distintos entre diversos titulares -racionalmente determinados como 'funciones' en el caso de legalidad (división constitucional de poderes) - de modo que sus disposiciones sólo sean legítimas, en los asuntos que corresponden a varios, si se forman por un compromiso" (p. 227).

14 Los organismos de control no se enmarcan en ninguna rama del poder público. Su regulación constitucional es autónoma.

15 El banco central no se enmarca en ninguna rama del poder público. Su regulación constitucional es autónoma.

16 Tal como lo establece la Constitución Bolivariana de Venezuela, promulgada en 1999 con la llegada al poder de Hugo Chávez. 
prejuicio. Por ende, sus acuerdos sobre los principios de la justicia nunca equivaldrían a un "juego de suma cero", en la cual, si unos tienen un privilegio, otros se verán desprovistos de aquel. Esta forma de abordar los principios de justicia en una sociedad es lo que el autor denomina justicia equidad (justice as fairness) que podría producir, como lo indica Nozick (1974), un "principio de justicia retributivo o, incluso, uno de justicia distributiva inversa, del mismo modo y bajo los mismos supuestos que obligarían a tomar la justicia distributiva o social" (Rodríguez, 2016).

Revisando la obra de Rawls, Sandel (2008) ${ }^{17}$ concluye que las personas que pacten los principios de justicia del contrato social descartarán el utilitarismo y el libertarismo, pues, siendo racionales, estos conceptos no los benefician. Los principios que se acordarían serían el de libertad y el de diferenciación; el de libertad implica que las libertades civiles universales (libertad religiosa, libertad de expresión, libertad de conciencia, entre otras) fueran asequibles para todos, mientras que el de diferenciación implica que la distribución equitativa de la riqueza no es necesaria ni conveniente y que solo se permiten inequidades para el beneficio de los menos favorecidos en la sociedad. En tal sentido, Rawls no discrepa sobre el hecho de que las personas puedan beneficiarse de "la lotería de la vida", entendida esta como la suerte de haber nacido en familias, lugares o entornos benéficos que determinarán sus condiciones futuras, siempre que ello se haga beneficiando a quienes más lo necesitan en la sociedad.

Dentro de los múltiples críticos ${ }^{18}$ de la teoría de la justicia de Rawls, quizá la crítica de Amartya Sen es la que resulta más relevante para el estudio del problema que plantea este trabajo. Sen (2009) plantea una serie de críticas que pueden ser efectivamente manejadas e interpretadas y otras que requieren un replanteamiento de las bases teóricas del trabajo de Rawls.

Respecto de las primeras, indica Sen (2009) que la priorización absoluta de la libertad sobre otros bienes sociales puede ser nocivo. Señala, por ejemplo, que la libertad de conciencia o religiosa, o cualquier tipo de libertad, no puede ser más importante en una sociedad que impedir que sus miembros mueran de hambre o desnutrición, lo cual sería un desarrollo consecuencial del principio de diferenciación (p. 65). Asimismo, indica que, para demostrar el principio de diferenciación

17 Michael Sandel es profesor Anne T. and Robert M. Bass de Gobierno en la Universidad de Harvard y autor de la obra Justice: Whats the right thing to do.

18 La teoría de la justicia de Rawls ha sido criticada por autores como Ronald Dworkin, Gerald Cohen, Philippe van Parijs, Robert Nozick y Amartya Sen. 
y las oportunidades que tienen las diferentes personas en la sociedad, Rawls solo toma en consideración los bienes que estas poseen y no las variaciones existentes que se dan al procurar convertir bienes primarios en calidad de vida. Indica, en este sentido, que no sería lógico pensar que un discapacitado físico con el mismo ingreso que una persona sin discapacidad pueda encontrarse en las mismas condiciones y tener las mismas oportunidades (p. 66).

Respecto de las segundas, Sen (2009) cuestiona la aproximación contractualista de Rawls al sistema de justicia y las contrasta con una posición "adamsmithiana" en cuanto al surgimiento silvestre de esta ante los diferentes fenómenos de equidad, y guiada por una mano invisible ante espectadores imparciales como mecanismo de control social. Cuestionar el contrato social, como origen de los principios fundadores de la justicia, permitiría reconocer los cambios sociales que requieren posiciones judiciales no previstas en el momento del pacto social, tomar en consideraciones posturas de personas no partícipes del contrato social, entre otras. Asimismo, alejarse del modelo contractualista implicaría permitir la aceptación teórica de la justicia internacional en un entorno global, pues esta no podría surgir del mismo presupuesto contractual que la justicia imperante en una sociedad de personas (p. 71).

Ahora bien, la teoría de la justicia de Rawls sirve como base para explicar el problema expuesto desde el título de este artículo, el cual busca determinar si la delegación permanente de funciones jurisdiccionales a las superintendencias colombianas vulnera los derechos humanos. Esta teoría trae dos importantes elementos que deben ser considerados: el primero es el relativo a la existencia o no de un contrato social hipotético que delimita y legitima los principios de justicia imperantes en nuestra sociedad y el segundo es el principio del igual acceso a las libertades (judiciales) como condición sine qua non para la existencia de un sistema justo.

La existencia (aún hipotética) de un contrato social requiere los elementos básicos de cualquier tipo de contrato: la existencia de una causa y un objeto contractual, ${ }^{19}$ la existencia de las partes, los derechos y las obligaciones que este

19 El objeto contractual difiere mucho en las teorías contractualistas de Hobbes y Locke con aquella de Rawls. Mientras para los primeros el contrato social era el acuerdo para regular los términos de la asociación política, para el último el objeto contractual se basaba en los principios de justicia necesarios para regular la estructura básica de la sociedad (la economía, la familia, la propiedad, entre otras) (Stanford Encyclopedia of Philosophy, 2017). 
confiere ${ }^{20}$ y el modelo de contrato. ${ }^{21}$ Aunque es claro que el contrato social es un "mito" 22 que pretende justificar la renuncia a las libertades básicas para un bienestar y protección común, es interesante ver cómo la existencia de esta figura ayuda a entender las más profundas fisuras que existen en los Estados actuales.

El segundo elemento, muy aunado al primero, es que el principio irrenunciable de justicia sobre el cual descansa el contrato social es el acceso equitativo a las libertades. Dicho acceso se ve claramente restringido cuando a ciertos administrados les es negado el derecho a comparecer frente a un juez imparcial, como es el caso de los procesos de desestimación de la personalidad jurídica promovidos por la Dirección de Impuestos y Aduanas Nacionales (DIAN) en contra de las sociedades que se hayan constituido para realizar actos fiscalmente fraudulentos. En este caso, la competencia para resolver judicialmente tales procesos ${ }^{23}$ recae en la Superintendencia de Sociedades que, como la DIAN, es una entidad perteneciente a la rama ejecutiva del poder público. En tal sentido, tanto el demandante como el juez serán parte del Gobierno (rama ejecutiva) y tendrán, en últimas, un mismo jefe (el presidente), frente al cual han de responder. Poca duda cabe respecto de la falta de independencia judicial que existe en este caso.

Ocurre también algo aún más irregular y es el proceso judicial de intervención administrativa de única instancia que puede tramitar la Superintendencia de So-

20 En el contrato social, las personas libres renuncian a su libertad absoluta y a poder hacer justicia por mano propia para entrar a ser gobernados por un ente jurídico superior, el cual les brindará seguridad y mantendrá la paz social, así como tendrá poder sobre ellos, sus propiedades, sus derechos y su libertad.

21 En la teoría de los contratos sociales, el elemento consensual (o el consentimiento o, en inglés, consent) desempeña un papel fundamental. Tan es así que, para Locke, solo las personas profusas en consentimiento podían ser parte del Gobierno. Esta estructura hipotética entra a presentar fisuras gracias a críticas como las de Ronald Dworkin, quien indica que nadie, en la actualidad, podría estar vinculado a este contrato social por falta de sucesión contractual. Por último, resulta curioso, desde la teoría contractual, que un contrato con semejantes efectos no fuera sujeto a negociación alguna (o en inglés bargain), y así resulta ser un contrato por adhesión en que no se entiende cuál es la parte fuerte y cuál la débil (Stanford Encyclopedia of Philosophy, 2017).

22 "El Estado, por ser un hecho dado en el escenario espacial, temporal y mental de las sociedades de hoy, es percibido como una realidad única y verdadera. Es un imaginario que da piso a las comunidades políticas que ha establecido el mundo moderno y que, en su repetición simbólica y material, creen en la institución estatal como el orden de todas las cosas de la vida social. El Estado ocupa el espacio geográfico de la vida de los hombres, a la manera de un espacio que le pertenece, lo controla y lo vigila y, en esa medida, ejerce soberanía, disciplina, jurisdicción y monopolio de la violencia sobre el territorio. El Estado, así, es una institución que obedece a un proceso de consolidación en un territorio. En suma, es una construcción, una invención" (Gómez y Ramírez, 2015, p. 27).

23 Véase Estatuto Tributario, art. 794-1 
ciedades en el Decreto 4334/2008, de 17 de noviembre. ${ }^{24}$ La Corte Constitucional, en Sentencia de Constitucionalidad no 145/09 de Corte Constitucional, 12 de marzo de 2009, avaló la constitucionalidad de las atribuciones jurisdiccionales antes establecidas, al considerar que, a pesar de ser ejercidas en única instancia, pueden ser excepcionalmente revisadas a través de la acción de tutela. ${ }^{25} \mathrm{Si}$ bien es cierto que los procesos judiciales de única instancia no vulneran per se los derechos fundamentales al debido proceso y al derecho de defensa, sí lo hacen cuando quien juzga no es un juez imparcial e independiente, y solo puede revisarse (o controlarse) la decisión a través de una tutela cuya procedencia, por cuestionar vías de hecho en una decisión judicial, es excepcionalísima. ${ }^{26}$ Así pues, claramente no puede entenderse el control vía tutela como una segunda instancia, razón por la cual estaría esta disposición violando el derecho humano a ser juzgado por un tribunal imparcial e independiente.

\section{Análisis económico del derecho: ¿la racionalidad económica permite la restricción de derechos fundamentales?}

Tal como lo concibió Adam Smith, el hombre en tanto ser racional concibe las decisiones humanas en función de la noción de provecho individual (Botero, 2016, pp. 19-53). El concepto de racionalidad económica es conocido como "el principio de que el individuo toma la mejor decisión dentro del conjunto de decisiones posibles" (Streb, 1998). Esta idea ha sido aplicada al ámbito de la justicia, no en su modalidad de utilitarismo, sino más como lo describe Sanchis i Marco (2018), como "principio de la eficiencia supeditado a la virtud de la justicia" (p. 2018).

El análisis económico del derecho ha estudiado la administración de justicia como "un mecanismo de asignación de recursos productivos en una sociedad" (Cabrillo, 2011, p. 1). Es precisamente este ente el que debe actuar racionalmen-

24 Este Decreto fue proferido con el propósito de dotar de herramientas jurídicas al Gobierno para combatir el fenómeno de las denominadas "pirámides" dedicadas a la captación masiva y habitual.

25 Véase Sentencia de Constitucionalidad n 145/09 de Corte Constitucional, 12 de marzo de 2009.

26 Véanse sentencias de Constitucionalidad n 590/05 y nº 038/17 de la Corte Constitucional. 
te, como un agente de mercado, sin incurrir, por ello, en un exceso de "activismo judicial". ${ }^{27}$ Así pues, autores como Richard Posner (1995) han sostenido que estos (los jueces) "actúan racionalmente en el sentido de que maximizan funciones de utilidad, como cualesquiera otros agentes que actúan en la vida económica" (Cabrillo, 2011, p. 5). Y como administradores de justicia deben realizar permanentemente un ejercicio de ponderación y adjudicación de múltiples factores.

Los principios que marcan de forma preponderante el ejercicio jurisdiccional son los de gratuidad, imparcialidad, celeridad, eficiencia, eficacia, razonabilidad y proporcionalidad. Estos postulados "han de ser aplicados con extremo rigor durante todas las fases del proceso" (Sentencia SP4198-2019/49222 de octubre 2 de 2019). Dentro de estos principios, no hay unos que prevalezcan sobre otros, es decir, no hay unos que tengan mayor grado o rango que los demás, ni unos cuya aplicación pueda dar lugar a la no aplicación de los restantes.

No pueden, tal como lo indica Rawls, las instituciones mantenerse vivas si, a pesar de tener estas virtudes, son injustas, aunque los principios de eficiencia, celeridad y eficacia tienen una importancia suprema en el concepto de justicia. Esto conduciría a lo que Chevallier (2011) ha denominado una "sociedad de la desconfianza", una sociedad donde los ciudadanos abdican a sus medios originales de arreglo directo de los problemas, para que las instituciones judiciales los resuelvan por ellos, basándose en una proliferación de normas al estilo francés y en una proliferación de acciones contenciosas al estilo americano.

La Corte Constitucional, en Sentencia de Tutela no 467/19 de Corte Constitucional, 8 de octubre de 2019, haciendo referencia a las tesis expuestas en la Sentencia de Constitucionalidad no 436/13 de Corte Constitucional, 10 de julio de 2013 y la Sentencia de Constitucionalidad no 896/12 de Corte Constitucional, 31 de octubre de 2012, adoptó un requisito adicional ${ }^{28}$ para la atribución de funciones jurisdiccionales a autoridades administrativas, el cual está basado, exclusivamente, en el análisis económico del derecho: la regla de eficiencia. ${ }^{29} \mathrm{Con}$

27 El término activismo judicial se entiende como "las decisiones de los órganos de la Administración de justicia que van más allá de la estricta aplicación de la ley, para extender algunos de sus principios a situaciones nunca previstas por el legislador" (Cabrillo, 2011).

28 Véase Corte Constitucional, Sentencia de Tutela $n^{\circ}$ 302/11 de Corte Constitucional, 28 de abril de 2011,.

29 Establece la Sentencia de Constitucionalidad n 436/13 de Corte Constitucional, 10 de julio de 2013 que "la atribución de una función judicial a las autoridades administrativas demanda que los asuntos sometidos al conocimiento de las autoridades administrativas sean resueltos de manera adecuada y eficaz. El cumplimiento de esta condición puede identificarse, entre 
esto se regresa al planteamiento inicial respecto de que los valores en la justicia no priman unos sobre otros; es importante que la justicia opere con celeridad, eficiencia y eficacia, pero sin que por ello se sacrifique su independencia.

La delegación permanente de funciones jurisdiccionales en las superintendencias colombianas no es fruto del neoconstitucionalismo ${ }^{30}$ ni del neocorporativismo, ${ }^{31}$ sino de una fractura profunda del Estado colombiano en que se ponderan los principios de eficiencia, eficacia y celeridad, relacionados con el concepto de justicia sobre los de imparcialidad y razonabilidad. En tal sentido, si bien práctico, no resuelve esta estructura el dilema de la adjudicación justa, pues de nada sirve una justicia pronta y eficaz si es proporcionada por un juez que no es independiente.

\section{Génesis y desarrollo de la delegación permanente de funciones jurisdiccionales a las superintendencias colombianas}

Pocas referencias existen a la delegación de funciones jurisdiccionales antes de la Constitución de 199132 (Ramírez y Hernández, 2018, pp. 317-350). Fue la

otras cosas, a partir de la relación de afinidad entre las funciones jurisdiccionales conferidas por la ley, y aquellas que ejerce ordinariamente el órgano correspondiente, cuando lo hace en sede administrativa. Una relación temática lejana entre las funciones administrativas y las funciones judiciales a cargo de una autoridad constituye un indicio de violación del mandato de asignación eficiente".

30 Según Comanducci (2009), "el neoconstitucionalismo, como teoría del derecho, aspira a describir los logros de la constitucionalización, es decir, de ese proceso que ha comportado una modificación de los grandes sistemas jurídicos contemporáneos respecto a los existentes antes del despliegue integral del proceso mismo. El modelo de sistema jurídico que emerge de la reconstrucción del neoconstitucionalismo está caracterizado, además de por una Constitución 'invasora', por la positivización de un catálogo de derechos fundamentales" (p. 83).

31 Para De Sousa-Santos (1998), la expresión neocorporativismo es "una nueva forma de pluralismo jurídico en las sociedades capitalistas avanzadas [...] [en que] los grupos neocorporativistas más organizados llegan a tener poder político suficiente para imponer tutelas jurisdiccionales diferenciadas pero favorables a la dinámica interna de sus intereses" (p. 217).

32 Aquí los autores indican que una entidad administrativa, como lo es la Superintendencia de Industria y Comercio, ha tenido funciones eminentemente jurisdiccionales, tal como lo es la protección del consumidor, desde la expedición de la Ley 155/1959, de 24 de diciembre y del Decreto 3466/1982, de 2 de diciembre. Con posterioridad, tales funciones fueron adicionadas mediante el Decreto 2153/1992, de 30 de diciembre y, finalmente, fueron reguladas íntegramente con la expedición de la Ley 1340/2009, de 24 de julio. 
necesidad de garantizar el acceso a la justicia lo que llevó al constituyente de 1991 a considerar que los jueces de paz, los comisarios, los inspectores de policía, los notarios y los superintendentes pudieran ser, excepcionalmente, investidos de poderes para impartir justicia dentro de la idea de colaboración armónica de las diferentes ramas del poder público y del poder unitario e indivisible del Estado. ${ }^{33}$ Si bien el criterio de otorgar facultades jurisdiccionales a entidades altamente especializadas, técnicas y calificadas es el adecuado, puede existir una fisura en la designación y garantía de juez imparcial.

Indica el artículo 116 de la Constitución Política que "excepcionalmente la Ley podrá atribuir función jurisdiccional en materias precisas a determinadas autoridades administrativas". Por excepcional, como lo indica el Diccionario de la lengua española (Real Academia Española [RAE], 2004), debemos entender aquel adjetivo que indica que algo "constituye excepción de la regla común" o "se aparta de lo ordinario, o que ocurre rara vez". Sin embargo, la realidad colombiana ha demostrado que la excepcionalidad en materia de delegación de funciones jurisdiccionales a las superintendencias colombianas constituye hoy una regla, más que una excepción.

La Ley 270/1996, de 7 de marzo, ${ }^{34}$ en su artículo 8, estableció que las autoridades administrativas podían conocer asuntos que por su naturaleza o cuantía pudieran resolverse por ellas de forma eficaz y adecuada, y que, en caso tal, la ley debería establecer de forma clara las competencias, garantías procesales y demás condiciones para proteger los derechos procesales de las partes.

Desde 1992, la Corte Constitucional ha venido analizando el fenómeno de la delegación de facultades jurisdiccionales en entidades administrativas. Si bien en un primer momento ${ }^{35}$ la Corte prohijó tal fenómeno casi de forma incondicional, en un segundo momento advirtió sobre los peligros que podría tener esta figura para las garantías constitucionales de ser juzgado por un juez imparcial (Rodríguez y Bejarano, 2018, p. 28) ${ }^{36}$ y, por ende, de tener derecho al debido proceso

33 Para Kelsen (2015), el poder del Estado es unitario e indivisible, pero se compone de tres poderes coordinados e independientes.

34 Modificada por el artículo 3 de la Ley 1285/2009, de 22 de enero.

35 Véase Sentencia de Constitucionalidad n 592/92 de Corte Constitucional del 7 de diciembre de 1992 y Sentencia de Constitucionalidad n 212/94 de Corte Constitucional del 28 de abril de 1994.

36 En Sentencia de Constitucionalidad no 141/95 de Corte Constitucional, 29 de marzo de 1995, mediante la cual se estudió la exequibilidad del artículo 656 del Decreto 2550/1998, de 15 de diciembre (integración del Consejo Verbal de Guerra), la Corte señaló que "la administración 
(p. 29). ${ }^{37}$ Posteriormente la Corte, en sus fallos, se ha limitado a establecer cuáles son las características de la delegación de las facultades jurisdiccionales. Así pues, ha establecido que a las autoridades administrativas las cobija el principio de unidad jurisdiccional, ${ }^{38}$ que el carácter excepcional de la delegación puede ser permanente ${ }^{39}$ y que la delegación no puede ser genérica o en abstracto. ${ }^{40}$ Quizá la posición más contundente establecida por la Corte Constitucional en esta materia fue la establecida en la Sentencia de Constitucionalidad no 833/06 de Corte Constitucional, 11 de octubre de 2006, cuando la entidad se pronunció "sobre la necesidad de conciliar las funciones jurisdiccionales en organismos administrativos con la debida imparcialidad que se espera de cualquier órgano que imparta justicia" (Rodríguez y Bejarano, 2018, p. 34). Así fue como estableció que "la Ley puede conferir atribuciones judiciales a las autoridades administrativas, pero siempre y cuando los funcionarios que ejercen concretamente esas competencias no solo se encuentren previamente determinados en la Ley sino que gocen de la independencia e imparcialidad propia de quien ejercita una función judicial".

A partir de estos pronunciamientos jurisprudenciales, las diferentes superintendencias han adoptado posturas de acogimiento parcial o, al menos, teórico

de justicia no solo reclama un juez conocedor de la problemática sobre la cual debe emitir sus fallos [...] sino también un juez objetiva e institucionalmente libre [...] El criterio de independencia también resulta afectado toda vez que el funcionario administrativo investido de funciones judiciales, está supeditado a los derroteros establecidos por el Superintendente, quien ha tenido injerencia previa y directa en el desarrollo de las funciones de control, inspección y vigilancia".

37 Véase Sentencia de Constitucionalidad n $1641 / 00$ de Corte Constitucional 29 de noviembre de 2000

38 En Sentencia de Constitucionalidad n 415/02 de Corte Constitucional, 28 de mayo de 2002, estableció la Corte Constitucional que, en virtud del principio de unidad jurisdiccional, "dichas entidades comienzan a compartir la estructura jurisdiccional de quien tenía la competencia originalmente", razón por la cual se abre la apelación ante el superior jurídico del órgano judicial desplazado.

39 En Sentencia de Constitucionalidad n ${ }^{\circ} 1071 / 02$ de Corte Constitucional, 3 de Diciembre de 2002, estableció la Corte Constitucional que "ese carácter excepcional no significa que a las autoridades administrativas no se les puedan atribuir funciones jurisdiccionales permanentes, pues lo excepcional no es aquello que no reviste el carácter de permanente sino aquello que constituye una excepción de la regla general".

40 En Sentencia de Constitucionalidad n 156/13 de Corte Constitucional, 20 de marzo de 2013, al declarar la inexequibilidad de la disposición del Código General del Proceso que atribuía funciones jurisdiccionales al Ministerio de Justicia, estableció la Corte Constitucional que "el aparte examinado prevé una asignación genérica, abierta y altamente indeterminada que no evidencia examen o valoración de ninguna naturaleza en relación con los efectos de la atribución de funciones jurisdiccionales al Ministerio". 
sobre este asunto. ${ }^{41}$ No obstante, siguen adelantándose casos en que se desvirtúa la posición teórica adoptada.

\section{La politización judicial en la Colombia del siglo XXI}

La independencia judicial es el refinamiento máximo de la justicia. En tal sentido, no puede hablarse de una justicia independiente cuando esta está politizada. Pensadores como Posner (2007, p. 820) indicaban que el beneficio social real de un poder judicial independiente es un elemento indispensable del imperio de la ley y que los jueces, como otras personas, tratan de maximizar su utilidad. Esta maximización se da por razones, como ocio, prestigio o poder (p. 825).

Es bien sabido que las funciones de un juez como órgano de actividad jurisdiccional del Estado son la de aplicar la norma jurídica al caso concreto, interpretarla según su sentido, alcance y finalidad, e integrar el orden jurídico cuando encuentre lagunas o vacíos (Ministerio de Justicia, 1988, p. 90). Así pues, dado que, según Aristóteles (trad. en 1954), el hombre es un animal político, cobra, por ello, especial vigencia la tesis central de la sentencia Marbury v. Madison según la cual "decir el derecho es por excelencia el ámbito y el deber del poder judicial" (Chevallier, 2011, p. 188).

La injerencia de la política en la justicia colombiana se acrecentó con la aprobación de la Constitución de 1991. En la Constitución de 1886, el empleo de magistrado de la Corte Suprema era vitalicio, a menos que ocurriere la destitución de este por mala conducta (Constitución Política de 1886, art. 147). Asimismo, tanto la elección del presidente de esta (art. 148) como el nombramiento y la remoción de sus "empleados subalternos" se hacía por la misma Corte Suprema de Justicia (art. 142). Este mecanismo, denominado cooptación, permitía la ver-

41 La Superintendencia de Sociedades, en Oficio 220-082746 del 26 de julio de 2019 indicó que "la jurisprudencia constitucional vertida en la sentencia C-1641 del 29 de noviembre de 2000, M. P. Alejandro Martínez Caballero, advierte que no le es dable a esta Superintendencia, como autoridad administrativa, intervenir en asuntos que haya de conocer en ejercicio de facultades jurisdiccionales, en relación con las cuales se debe pronunciar como juez en las instancias procesales a que haya lugar". 
dadera independencia de la rama judicial, y así se generaba una real separación entre el poder judicial y las otras ramas del poder público.

La Constitución de 1991, en busca de la eficacia, la independencia, el control judicial del poder y la accesibilidad (Jost, 2011, p. 397), introdujo una reforma sustancial al aparato de justicia colombiano. Bajo estas premisas, fueron creadas entidades como la Corte Constitucional, el Consejo Superior de la Judicatura y la Fiscalía General de la Nación, con lo cual se logró el cometido de la eficacia y del control judicial del poder, y mecanismos tales como la acción de tutela, con lo cual, ciertamente, se impulsó la accesibilidad. No obstante, al erradicar el mecanismo de cooptación y delegar la escogencia de los magistrados de las Cortes en el Congreso de la República, por ternas presentadas por el presidente de la república, la justicia en Colombia, lejos de democratizarse, se politizó. ${ }^{42} \mathrm{Al}$ darse esta politización, ${ }^{43}$ se perdió naturalmente la independencia judicial hasta el punto de hallar razón en el dicho de Peretti (2003, pp. 86-106), según el cual "los jueces tienen la independencia que los políticos estén dispuestos a concederles".

La creación de la Jurisdicción Especial para la Paz (JEP), órgano acordado en los diálogos de La Habana en la negociación de la paz con las Fuerzas Armadas Revolucionarias de Colombia (FARC) y elevado a rango constitucional, ${ }^{44}$ terminó de definir la constelación de los órganos de cierre del poder judicial. Su existencia ha sido duramente criticada, hasta el punto de que sectores políticos han sugerido la realización de una asamblea nacional constituyente a efectos de reformar la Constitución y adoptar nuevamente una estructura de una sola gran Corte, ora con pocos magistrados (modelo americano), ora con múltiples salas (modelo venezolano) (Botero, 2017), para que no existan "choques de trenes" entre las máximas instancias del poder judicial en Colombia.

42 Basta para ello recordar el episodio cuando la Corte Suprema de Justicia de Colombia, por su animadversión con el Gobierno de Álvaro Uribe Vélez, se negó sistemáticamente a votar la terna presentada por el entonces presidente, y la devolvió alegando falta de imparcialidad en los candidatos presentados (Semana, 2009).

43 De ahí la famosa frase que se le atribuye al exmagistrado de la Corte Constitucional Mauricio González Cuervo: "El presidente me puso en la terna para que fuese un juez imparcial y tengo que cumplirle".

44 El Acto Legislativo 1/2017, de 4 de abril crea el Sistema Integral de Verdad, Justicia, Reparación y No Repetición, compuesto por la Jurisdicción Especial para la Paz (JEP), la Comisión de la Verdad y la Unidad de Búsqueda de Desaparecidos. 


\section{El bloque de constitucionalidad y el concepto de debido proceso según la Declaración Universal de Derechos Humanos y el Sistema Interamericano de Derechos Humanos}

La Declaración Universal de los Derechos Humanos indica, en su artículo 11, que "toda persona tiene derecho, en condiciones de plena igualdad, a ser oída públicamente y con justicia por un tribunal independiente e imparcial [las cursivas son mías], para la determinación de sus derechos y obligaciones". Asimismo, la Convención Americana sobre Derechos Humanos señala, en su artículo 8.1, que "toda persona tiene derecho a ser oída, con las debidas garantías y dentro de un plazo razonable, por un juez o tribunal competente, independiente e imparcial [las cursivas son mías]". Ambos tratados han sido expresamente ratificados por Colombia, ${ }^{45}$ y como tratados internacionales ratificados por el Congreso que reconocen derechos humanos, en virtud de lo expuesto en el artículo $93^{46}$ de la Constitución Política, prevalecen sobre el ordenamiento jurídico interno y hacen parte del bloque de constitucionalidad. ${ }^{47}$

Ahora bien, sobre derechos humanos, ¿qué ha de entenderse por un tribunal imparcial e independiente? La imparcialidad judicial implica que "el juzgador debe ser extrańo a los intereses de ambas partes y estar aislado de toda influencia que pueda desviar su juicio" (Claría, 1988, p. 207), y que deba ser inerte. ${ }^{48} \mathrm{La}$ imparcialidad judicial ha sido ampliamente estudiada por el Tribunal Europeo de Derechos Humanos (TEDH) (Bordalí, 2009, pp. 263-302) que ha clasificado

45 El Pacto de San José fue ratificado por Colombia, y adoptado como legislación permanente mediante la Ley 16/1972, de 30 de diciembre.

46 "Los tratados y convenios internacionales ratificados por el Congreso, que reconocen los derechos humanos y que prohíben su limitación en los estados de excepción, prevalecen en el orden interno. Los derechos y deberes consagrados en esta Carta, se interpretarán de conformidad con los tratados internacionales sobre derechos humanos ratificados por Colombia" (Constitución Política, art. 93).

47 El bloque de constitucionalidad "se refiere a aquellas normas y principios que, sin aparecer formalmente en el articulado del texto constitucional, son utilizados como parámetros del control de constitucionalidad de las leyes, por cuanto han sido normativamente integrados a la Constitución, por diversas vías y por mandato de la propia Constitución" (Arango, 2004, p. 79).

48 Según Calamandrei (2001), "la inercia es en juez garantía de su equilibrio, esto es, imparcialidad" (pp. 24-25, 54-55). 
este concepto en imparcialidad subjetiva ${ }^{49}$ y objetiva ${ }^{50}$ y definido los criterios de cuándo un juez debe abstenerse de actuar en un proceso por no ser imparcial. ${ }^{51}$ La independencia, a su vez, le impide al juez "depender en su decisión de criterios o intereses de estas [de las partes], o de personas o instituciones ajenas al proceso. Es decir, el juzgador en su deber de dirección no debe permitir influencias en la toma de decisiones" (Picado, 2014, p. 59).

La obligación del juez de conservar su independencia e imparcialidad está consagrada en múltiples convenios y tratados internacionales, muchos de los cuales tienen jerarquía de norma constitucional por hacer parte del bloque de constitucionalidad. Así es como el Estatuto del Juez Iberoamericano, ${ }^{52}$ la Declaración Universal de Derechos Humanos, ${ }^{53}$ la Declaración Americana de los Derechos y Deberes del Hombre, ${ }^{54}$ el Pacto Internacional de Derechos Civiles y Políticos, ${ }^{55}$ los Principios básicos relativos a la independencia de la judicatura ${ }^{56}$ y la Conven-

49 Se refiere este fenómeno al "posicionamiento personal de los jueces en los términos de las partes de una causa judicial" (Bordalí, 2009, p. 272) y "corresponderá a la parte que se lamenta de la parcialidad del magistrado demostrarla, probando en concreto que la disposición anímica o psicológica del juez y su conducta exteriorizada son síntomas de falta de imparcialidad" (p. 273).

50 Respecto de este fenómeno ha indicado la doctrina que "con la imparcialidad objetiva no se trata ya que el juez haya exteriorizado convicción personal alguna ni haya tomado partido previo, sino que estamos frente a un juez que no ofrece garantías suficientes para excluir toda duda legítima al respecto. Por eso, en esta perspectiva, importan sobremanera las consideraciones de carácter funcional y orgánico, pues determinan si, por las funciones que se le asignan al juez en el proceso, puede este ser visto como un tercero ajeno a los intereses que en él se ventila" (Bordalí, 2009, p. 273).

51 "En su decisión sobre el caso 'De Cubber', de 26 de octubre de 1984, y ya antes en el caso 'Piersack', del 1 de octubre de 1982, [el TEDH] ha marcado la importancia que en este caso tienen las apariencias, de forma que debe abstenerse todo Juez del que pueda temerse legítimamente una falta de imparcialidad, pues va en ello la confianza que los Tribunales de una sociedad democrática han de inspirar a los justiciables" (Picado, 2014, p. 59).

52 El artículo 3 de este convenio establece que "la utilización de medios de comunicación social con el objeto de suplantar funciones jurisdiccionales, imponer o influir el contenido de las resoluciones judiciales, en condiciones que excedan el legítimo derecho a la libertad de expresión e información, se considera lesiva para la independencia judicial".

53 El artículo 10 de este convenio establece que "toda persona tiene derecho, en condiciones de plena igualdad, a ser oída públicamente y con justicia por un tribunal independiente e imparcial para la determinación de sus derechos y obligaciones o para el examen de cualquier acusación contra ella en materia penal".

54 El título XXVI de este convenio establece que "toda persona acusada de un delito tiene derecho a ser oída en forma imparcial y pública".

55 El artículo 14, inciso 1, de esta convención establece que "toda persona tendrá derecho a ser oída públicamente y con las debidas garantías por un tribunal competente, independiente e imparcial establecido por Ley".

56 Estos principios adoptados por el Séptimo Congreso de las Naciones Unidas sobre Prevención del Delito y Tratamiento del Delincuente, celebrado en Milán del 26 de agosto al 6 de sep- 
196 | ¿La delegación permanente de funciones jurisdiccionales a las superintendencias colombianas vulnera los derechos humanos?

ción Americana sobre Derechos Humanos ${ }^{57}$ exigen expresamente que quien vaya a juzgar una causa esté dotado de plena independencia e imparcialidad (Picado, 2014, p. 53).

La jurisprudencia de la Corte Interamericana de Derechos Humanos (Corte IDH) ha contribuido a aclarar cómo deben materializarse los principios de independencia a imparcialidad en los diferentes sistemas jurídicos para garantizar el derecho al debido proceso. Indica esta Corte que, para que exista una real independencia judicial, es necesario que los ordenamientos jurídicos cumplan con criterios tales como la estabilidad, ${ }^{58}$ la inamovilidad, ${ }^{59}$ la garantía contra presiones externas $^{60}$ y el adecuado proceso de nombramiento basados en criterios objetivos para su selección. ${ }^{61}$ Respecto de la imparcialidad ha dicho la Corte IDH que esta

tiembre de 1985, y confirmados por la Asamblea General en sus resoluciones 40/32 de 29 de noviembre de 1985 y 40/146 de 13 de diciembre de 1985, establece en su principio 2 que "los jueces resolverán los asuntos que conozcan con imparcialidad, basándose en los hechos y en consonancia con el derecho, sin restricción alguna y sin influencias, alicientes, presiones, amenazas o intromisiones indebidas, sean directas o indirectas, de cualesquiera sectores o por cualquier motivo". Asimismo, el principio 1 indica que "la independencia de la judicatura será garantizada por el Estado y proclamada por la Constitución o la legislación del país. Todas las instituciones gubernamentales y de otra índole respetarán y acatarán la independencia de la judicatura".

57 El artículo 8.1 de esta convención establece que "toda persona tiene derecho a ser oída, con las debidas garantías y dentro de un plazo razonable, por un juez o tribunal competente, independiente e imparcial establecido con anterioridad por la Ley".

58 Véase Corte Interamericana de Derechos Humanos Caso Apitz Barbera y otros ("Corte Primera de lo Contencioso Administrativo") vs. Venezuela en que se establece que, para mantener la independencia, es indispensable "otorgarles [a los jueces, así sean provisorios] cierto tipo de estabilidad y permanencia en el cargo, puesto que la provisionalidad no equivale a libre remoción".

59 En igual sentido, el Comité de Derechos Humanos de las Naciones Unidas, en su Observación General N. ${ }^{\circ}$ 32, artículo 14, indicó que "la destitución de jueces por el Poder Ejecutivo antes de la expiración del mandato para el que fueron nombrados, sin que se les dé ninguna razón concreta y sin que dispongan de una protección judicial efectiva para impugnar la destitución es incompatible con la independencia judicial".

60 Véase Corte Interamericana de Derechos Humanos Caso Reverón Trujillo vs. Venezuela. El derecho a la inamovilidad se entiende como la imposibilidad de los Estados, especialmente de la rama ejecutiva, "de intervenir en el poder judicial sin mayores costos o control. [...] La inamovilidad de los jueces provisorios está estrechamente ligada a la garantía contra presiones externas, ya que si los jueces provisorios no tienen la seguridad de permanencia durante un periodo determinado, serán vulnerables a presiones de diferentes sectores, especialmente de quienes tienen la facultad de decidir sobre destituciones o ascensos". Igualmente importante, a efectos de garantizar la independencia, es que los jueces puedan discutir judicialmente las decisiones por las cuales se les obliga a dejar su cargo, no siendo el libre nombramiento y la remoción una justa causa para cesar del cargo a un juez.

61 Véase Corte Interamericana de Derechos Humanos Caso Reverón Trujillo vs. Venezuela en que se establece que, "si el acceso a la administración pública se basa en los méritos y en la 
“implica que sus integrantes no tengan un interés directo, una posición tomada, una preferencia por alguna de las partes y que no se encuentren involucrados en la controversia" ${ }^{2}$ y que "el juez debe aparecer como actuando sin estar sujeto a influencia, aliciente, presión, amenaza o intromisión, directa o indirecta, sino única y exclusivamente conforme a $-\mathrm{y}$ movido por- el Derecho". ${ }^{63}$

\section{Control de convencionalidad, derechos humanos y statu quo de la justicia delegada en Colombia}

Al haber suscrito y ratificado Colombia la Convención Americana de Derechos Humanos $(\mathrm{CADH})$, su poder judicial interno debe, necesariamente, "velar por que los efectos de las disposiciones de la Convención no se vean mermadas por la aplicación de leyes contrarias a su objeto y fin, y que desde un inicio carecen de efectos jurídicos". ${ }^{64}$ La herramienta para hacer esto se denomina control de convencionalidad, y debe ser realizada por el operador judicial "quien no solo debe limitarse a realizar un examen de constitucionalidad de sus resoluciones, sino también de convencionalidad" ${ }^{65}$

El estado actual de la justicia delegada a entes administrativos en Colombia no cumple con los requisitos establecidos por la Corte IDH para asegurar la independencia e imparcialidad del juez, con ello se viola la CADH y otras convenciones de derechos humanos. Lo anterior por cuanto los funcionarios judiciales que imparten justicia desde las diferentes superintendencias: a) no cuentan con un régimen de estabilidad que les permita adoptar libremente sus decisiones sin preocuparse por las consecuencias que ello pueda conllevar respecto de sus superiores

igualdad de oportunidades, y si se asegura la estabilidad en el cargo, se garantiza la libertad de toda injerencia o presión política [...] La igualdad de oportunidades se garantiza a través de una libre concurrencia, de tal forma que todos los ciudadanos que acrediten los requisitos determinados en la Ley deben poder participar en los procesos de selección sin ser objeto de tratos desiguales o arbitrarios".

62 Corte Interamericana de Derechos Humanos Caso Palamara Iribarne vs. Chile.

63 Véase Corte Interamericana de Derechos Humanos Caso Norín Catrimán y otros (dirigentes, miembros y activista del pueblo indígena mapuche) vs. Chile.

64 Véase Corte Interamericana de Derechos Humanos Caso Almonacid Arellano y otros vs. Chile.

65 Véase Corte Interamericana de Derechos Humanos Caso Almonacid Arellano y otros vs. Chile. 
jerárquicos; b) son funcionarios de libre nombramiento y remoción; c) no existen políticas efectivas que eviten que dichos funcionarios sean presionados interna $o$ externamente, ni que puedan cuestionar o discutir judicialmente la decisión de ser desvinculados unilateralmente; $\mathrm{y}$ d) su proceso de selección y nombramiento no obedece a un proceso público en que pueda competirse por méritos, sino más bien a un proceso privado de selección directa.

La estructura actual de las diferentes superintendencias que realizan la inspección, la vigilancia y el control de sus supervisados y, al mismo tiempo, ejercen funciones jurisdiccionales carecen de un mecanismo jurídico apropiado para que los funcionarios que imparten justicia mantengan su imparcialidad. Este mecanismo implicaría, necesariamente, que no existiera subordinación respecto del superintendente y que dichos funcionarios no fueran enterados de las medidas administrativas que puedan estar tomando la misma entidad en contra de los sujetos procesales bajo su jurisdicción.

El proceso de delegación de facultades judiciales a entidades administrativas, lejos de contribuir a la separación de poderes mediante la colaboración armónica de estos, ha llevado a la concentración del poder judicial en manos del Ejecutivo. Esto, además de romper la estructura del Estado constitucional moderno, resulta violatorio de los derechos humanos de quienes acceden a la justicia, por no garantizarse la existencia de un juez independiente e imparcial.

Así pues, muchas de las decisiones judiciales que se están adoptando actualmente en las diferentes superintendencias se han hecho a través de mecanismos que carecen de las garantías básicas otorgadas por los tratados internacionales de derechos humanos. Dada esta realidad, quien discrepe de una providencia judicial por considerar que esta es fruto de un proceso que no respetó los cánones básicos del debido proceso y, por ende, resulta violatoria de los derechos humanos, puede solicitar la aplicación del régimen convencional a través del control de convencionalidad o demandar la responsabilidad del Estado ante los correspondientes organismos internacionales.

\section{Conclusiones}

Según Aguiló (1997), el juez independiente e imparcial es "el Juez obediente al Derecho". Este juez resulta, para la sociedad, un baluarte de moralidad y magnanimidad y, por ello, se ha idealizado y mitificado. Jueces (mitológicos y rea- 
les) como Hércules, Bayes, Olver Wendell Holmes Jr., Learned Hand, Henry Friendly, Duncan Kennedy, Richard Posner, Baltazar Garzón o Kai Ambos, teniendo diferentes virtudes, han enaltecido la profesión judicial por su independencia y su imparcialidad.

Tal como ha quedado demostrado, la delegación permanente de funciones jurisdiccionales a las superintendencias colombianas vulnera los derechos humanos contenidos en el artículo 8(1) de la CADH y en el artículo 11 de la Declaración Universal de los Derechos Humanos, pues no se garantiza en estas la independencia del juez. Esto ocurre, con mayor razón, cuando las funciones jurisdiccionales producen sentencias que no son susceptibles de revisión por un órgano judicial independiente, tal como ocurre con los casos de intervención por captación de recursos del público.

Colombia requiere una reforma estructural a su sistema de justicia. Tal reforma no debe velar simplemente por descongestionar el aparato estatal y mejorar la eficiencia de este, sino por depurar este de cualquier elemento que haga que el juez pierda independencia, incluida la delegación permanente de funciones a estos órganos. En reemplazo, podría crearse una jurisdicción mercantil cuyos jueces fueran verdaderos expertos en temas empresariales (temas societarios, concursales, financieros, de protección al consumidor, competencia desleal, entre otros), tal como lo estableció, por última vez, ${ }^{66}$ el Decreto 2273/1989, de 7 de octubre, el cual creó los jueces civiles del circuito especializados.

\section{Referencias}

Aguiló Regla, J. (1997). Independencia e imparcialidad de los jueces y argumentación jurídica. Isonomía, 6, 71-79. Recuperado de http://www.cervantesvirtual.com/research/independencia-e-imparcialidad-de-los-jueces-y-argumentacin-jurdica0/006303d8-82b2-11df-acc7-002185ce6064.pdf

Arango Olaya, M. (2004). El bloque de constitucionalidad en la jurisprudencia de la Corte Constitucional colombiana. Precedente: Revista Jurídica, 79-102. Recuperado de https://www.icesi.edu.co/revistas/index.php/precedente/issue/view/171

66 Según Vanegas y Barrera (2012), los antecedentes de la jurisdicción mercantil en Colombia "se remontan al siglo XIX [con] la Ley 10 de 1824" (p. 14). Posteriormente, tal jurisdicción es modificada por la Ley 23/1836, luego por el Código de Comercio de la Nueva Granada del 16 de junio de 1853 y, finalmente, por el Código de Comercio Marítimo de 1870, antes de expedirse el Decreto 2273/1989, de 7 de octubre. 
200 | ¿La delegación permanente de funciones jurisdiccionales a las superintendencias colombianas vulnera los derechos humanos?

Aristóteles. (1954). La política. Barcelona, España: Iberia.

Bordalí Salamanca, A. (2009). El derecho fundamental a un tribunal independiente e imparcial en el ordenamiento jurídico chileno. Revista de Derecho, 33, 263-302. http://dx.doi.org/10.4067/S0718-68512009000200007

Botero Cedeño, E. A. (2016). Reflexión sobre el concepto de racionalidad económica y noción del Homo oeconomicus. En Autor, Bases conceptuales para un análisis crítico del discurso administrativo y económico. (pp. 19-53). Bogotá, Colombia: Universidad Cooperativa de Colombia. Recuperado de https://repository.ucc.edu.co/ handle/20.500.12494/233

Botero Mariño, C. (2017, abril 5). Los riesgos de crear una única corte de justicia. Ámbito Jurídico. Recuperado de https://www.ambitojuridico.com/noticias/columnistaimpreso/constitucional-y-derechos-humanos/opinion-los-riesgos-de-crear-una

Bovero, M. (2000). Contro il governo dei peggiori: una grammatica della democracia. Bari, Italia: Laterza.

Cabrillo, F. (2011). Un análisis económico de la administración de justicia: ¿qué maximizan los jueces? En Derecho y economía. Lima, Perú: Universidad San Martín de Porres. Recuperado de http://www.usmp.edu.pe/derecho/centro_derecho_economia/revista/febrero_2011/Analisis_Economico_de_la_Adm._de_Justicia_Dr_Francisco_Cabrillo.pdf

Calamandrei, P. (2001). Elogio de los jueces escrito por un abogado. Ciudad de México, México: Oxford University Press.

Chevallier, J. (2011). El Estado posmoderno. Bogotá, Colombia: Universidad Externado de Colombia.

Clariá Olmedo, J. A. (1988). Derecho procesal: conceptos fundamentales. Buenos Aires, Argentina: Depalma.

Colli Ek, V. M. (2010). La magistratura estatal: evolución, consolidación y defensa en la interpretación constitucional de la Suprema Corte de Justicia de la Nación. Ciudad de México, México: Porrúa.

Comanducci, P. (2009). En M. Carbonell (Ed.), Neoconstitucionalismo(s). Madrid, España: Trotta. Págs. 75-98

Concha Mena, J. F., Hernández Castañeda, L. V. y Torres Ángel, M. J. (s. f.). Facultades jurisdiccionales a autoridades administrativas: el caso colombiano de la superintendencia de sociedades. Recuperado de vitela.javerianacali.edu. co/bitstream/handle/11522/10603/Facultades_jurisdiccionales_otorgadas. pdf? sequence $=1$ \&isAllowed $=y$

Constitución Política 1991, de 13 de junio, Constitución Política de 1991. Gaceta Constitucional, núm. 114 (1991).

Convención Americana sobre Derechos Humanos suscrita en la Conferencia Especializada Interamericana Sobre Derechos Humanos (B-32) San José, Costa Rica 7 al 22 de noviembre de 1969 Convención Americana sobre Derechos Humanos (Pacto de San José).

Corte Interamericana de Derechos Humanos Caso Almonacid Arellano y otros vs. Chile.

Corte Interamericana de Derechos Humanos Caso Apitz Barbera y otros ("Corte Primera de lo Contencioso Administrativo") vs. Venezuela.

Corte Interamericana de Derechos Humanos Caso Palamara Iribarne vs. Chile.

Corte Interamericana de Derechos Humanos Caso Norín Catrimán y otros (dirigentes, miembros y activista del pueblo indígena mapuche) vs. Chile. 
Corte Interamericana de Derechos Humanos Caso Reverón Trujillo vs. Venezuela.

De Sousa-Santos, B. (1998). De la mano de Alicia: lo social y lo político en la posmodernidad. Bogotá, Colombia: Siglo del Hombre.

Declaración Americana de los Derechos y Deberes del Hombre Aprobada en la Novena Conferencia Internacional Americana Bogotá, Colombia, 1948.

Declaración Universal de Derechos Humanos Adoptada y proclamada por la Asamblea General en su Resolución 217 A (III), de 10 de diciembre de 1948.

Decreto 3466/1982, de 2 de diciembre, por el cual se dictan normas relativas a la idoneidad, la calidad, las garantías, las marcas, las leyendas, las propagandas y la fijación pública de precios de bienes y servicios, la responsabilidad de sus productores, expendedores y proveedores, y se dictan otras disposiciones. Diario Oficial, núm. 36143 (1982).

Decreto 2651/1991, de 25 de noviembre, por el cual se expiden normas transitorias para descongestionar los despachos judiciales. Diario Oficial, núm. 40177 (1991).

Decreto 2153/1992, de 30 de diciembre, por el cual se reestructura la Superintendencia de Industria y Comercio y se dictan otras disposiciones. Diario Oficial, núm. 40704 (1992).

Decreto 2550/1998, de 15 de diciembre, por el cual se delega en el Ministro de Hacienda y Crédito Público la facultad para celebrar en nombre de la Nación un contrato de empréstito externo. Diario Oficial, núm. 43454 (1998).

Decreto 4334/2008, de 17 de noviembre, por el cual se expide un procedimiento de intervención en desarrollo del Decreto 4333 del 17 de noviembre de 2008. Diario Oficial, núm. 47176 (2008).

Estatuto del Juez Iberoamericano La VI Cumbre Iberoamericana de Presidentes de Cortes Supremas y Tribunales Supremos de Justicia, celebrada en Santa Cruz de Tenerife, Canarias, España, los días 23, 24 y 25 de mayo de 2001.

Estatuto Tributario Nacional. (s. f.). Recuperado de https://estatuto.co/?e=183

Gil Botero, E. (2019). Control de convencionalidad en Colombia: una experiencia de dia-

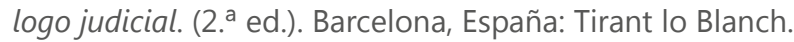

Gómez Alarcón, T. H. y Ramírez Jiménez, E. A. (2015). La ficción del Estado nación: configuración territorial del Estado en el departamento de Caquetá. Medellín, Colombia: Universidad de Antioquia. Recuperado de http://bibliotecadigital.udea.edu.co/ handle/10495/9807

Hierro, L. (2016). Los derechos humanos: una concepción de la justicia. Madrid, España: Marcial Pons.

Jost, S. (Ed.) (2011). 20 años de la Constitución colombiana: logros, retrocesos y agenda pendiente. Bogotá, Colombia: Fundación Konrad Adenauer. Recuperado de https:// www.kas.de/es/web/kolumbien/veranstaltungsberichte/detail/-/content/-20-anosde-la-constitucion-colombiana-logros-retrocesos-y-agenda-pendiente-

Kennedy, D. (1997). A critique of adjudication. Cambridge, EE. UU.: Harvard University Press.

Kennedy, D. (1999). Libertad y restricción en la decisión judicial: el debate con la teoría crítica del derecho. Bogotá, Colombia: Siglo del Hombre.

Lemos, C. (1998). Constitución Política de Colombia. Bogotá, Colombia: Panamericana.

Ley 155/1959, de 24 de diciembre, por la cual se dictan algunas disposiciones sobre practicas comerciales restrictivas. Diario Oficial, núm. 30138 (1960).

Ley 16/1972, de 30 de diciembre, por medio de la cual se aprueba la Convención 
202 | ¿La delegación permanente de funciones jurisdiccionales a las superintendencias colombianas vulnera los derechos humanos?

Americana sobre Derechos Humanos "Pacto de San José de Costa Rica", firmado en San José, Costa Rica el 22 de noviembre de 1969. Diario Oficial, núm. 33780 (1973).

Ley 23/1991, de 21 de marzo, por medio de la cual se crean mecanismos para descongestionar los Despachos Judiciales y se dictan otras disposiciones. Diario Oficial, núm. 39752 (1991).

Ley 270/1996, de 7 de marzo, estatutaria de la Administración de Justicia. Diario Oficial, núm. 42745 (1996).

Ley 446/1998, de 7 de julio, por la cual se adoptan como legislación permanente algunas normas del Decreto 2651 de 1991, se modifican algunas del Código de Procedimiento Civil, se derogan otras de la Ley 23 de 1991 y del Decreto 2279 de 1989, se modifican y expiden normas del Código Contencioso Administrativo y se dictan otras disposiciones sobre descongestión, eficiencia y acceso a la justicia. Diario Oficial, núm. 43335 (1998).

Ley 510/1999, de 3 de agosto, por la cual se dictan disposiciones en relación con el sistema financiero y asegurador, el mercado público de valores, las Superintendencias Bancaria y de Valores y se conceden unas facultades. Diario Oficial, núm. 43654 (1999).

Ley 1285/2009, de 22 de enero, por medio de la cual se reforma la Ley 270 de 1996 Estatutaria de la Administración de Justicia. Diario Oficial, núm. 47240 (2009).

Ley 1340/2009, de 24 de julio, por medio de la cual se dictan normas en materia de protección de la competencia. Diario Oficial, núm. 47420 (2009).

McIlwain, C. H. (1947). Constitutionalism: Ancient and modern. Ithaca, EE. UU.: Cornell University Press.

Nozick, R. (1974). Anarchy, state, and utopia. Nueva York, EE. UU.: Basic Books.

Oficio 220-082746 del 26 de julio de 2019.

Ortega J. R. (2019, octubre 3). Reforma a la justicia. Dinero. Recuperado de https://www. dinero.com/opinion/columnistas/articulo/reforma-a-la-justicia-por-juan-ricardoortega/277587

Pacto Internacional de Derechos Civiles y Políticos Adoptado y abierto a la firma, ratificación y adhesión por la Asamblea General en su resolución 2200 A (XXI), de 16 de diciembre de 1966 Entrada en vigor: 23 de marzo de 1976, de conformidad con el artículo 49 Lista de los Estados que han ratificado el pacto.

Picado Vargas, C. A. (2014). El derecho a ser juzgado por un juez imparcial. Revista de IUDEX, 2, 31-62. Recuperado de http://www.corteidh.or.cr/tablas/r32673-1.pdf

Portland Public Schools. (s. f.). División de poderes. Recuperado de http://www.pps.k12. or.us/district/depts/edmedia/videoteca/curso2/htmlb/SEC_94.HTM

Posner, R. A. (2007). El análisis económico del derecho. (2. ${ }^{a}$ ed.). Ciudad de México, México: Fondo de Cultura Económica.

Principios básicos relativos a la independencia de la judicatura Adoptados por el Séptimo Congreso de las Naciones Unidas sobre Prevención del Delito y Tratamiento del Delincuente, celebrado en Milán del 26 de agosto al 6 de septiembre de 1985, y confirmados por la Asamblea General en sus resoluciones 40/32 de 29 de noviembre de 1985 y 40/146 de 13 de diciembre de 1985.

Ramírez Torrado, M. L. y Hernández Meza, N. (2018). Análisis de las funciones administrativas y jurisdiccionales de la superintendencia de industria y comercio en materia de libre competencia. Revista Derecho del Estado, 41, 317-350. Recuperado de https://papers.ssrn.com/sol3/papers.cfm?abstract_id=3175985 
Rawls, J. (1999). A theory of justice. Cambridge, EE. UU.: Harvard University Press.

Rodríguez Herrera, D. (2016, diciembre 9). La utopía de Nozick. Recuperado de https:// www.mises.org.es/2016/12/la-utopia-de-nozick/

Rodríguez Mejía, M. y Bejarano Guzmán, R. (Eds.) (2018). Estudio de la delegación de funciones jurisdiccionales en la rama ejecutiva: una revisión global y particular. Bogotá, Colombia: Universidad Externado de Colombia.

Salazar Ugarte, P. (2006). La democracia constitucional: una radiografía teórica. Ciudad México, México: Fondo de Cultura Económica.

Sanchis i Marco, M. (2018). La justicia en economía: racionalidad económica y criterios de demarcación del estado social de justicia (Tesis doctoral, Universitat de València, València, España). Recuperado de http://roderic.uv.es/handle/10550/67944

Sandel, M. J. (2008). Justice: Whats the right thing to do. Londres, RU: Macmillan:

Sen, A. (2009). The idea of justice. Cambridge, RU: Harvard University Press.

Sentencia de Tutela n 502/92 de Corte Constitucional, 21 de agosto de 1992.

Sentencia de Constitucionalidad n 592/92 de Corte Constitucional, 7 de diciembre de 1992.

Sentencia de Constitucionalidad n 212/94 de Corte Constitucional, 28 de abril de 1994.

Sentencia de Constitucionalidad $n^{\circ}$ 141/95 de Corte Constitucional, 29 de marzo de 1995.

Sentencia de Constitucionalidad n 1641/00 de Corte Constitucional, 29 de noviembre de 2000.

Sentencia de Constitucionalidad $n^{\circ}$ 415/02 de Corte Constitucional, 28 de mayo de 2002.

Sentencia de Constitucionalidad n ${ }^{\circ} 833 / 06$ de Corte Constitucional, 11 de octubre de 2006.

Sentencia de Constitucionalidad n 145/09 de Corte Constitucional, 12 de marzo de 2009.

Sentencia de Tutela n 302/11 de Corte Constitucional, 28 de abril de 2011.

Sentencia de Constitucionalidad $n^{\circ}$ 1071/02 de Corte Constitucional, 3 de diciembre de 2002.

Sentencia de Constitucionalidad n $896 / 12$ de Corte Constitucional, 31 de octubre de 2012.

Sentencia de Constitucionalidad $n^{\circ}$ 156/13 de Corte Constitucional, 20 de marzo de 2013.

Sentencia de Constitucionalidad n 436/13 de Corte Constitucional, 10 de julio de 2013.

Sentencia SP4198-2019/49222 de octubre 2 de 2019.

Sentencia de Tutela n 467/19 de Corte Constitucional, 8 de octubre de 2019.

Solozábal Echavarría, J. J. (1981). Sobre el principio de la separación de poderes. Revista de Estudios Políticos, 24, 215-234. Recuperado de http://www.cepc.gob.es/publicaciones/revistas/revistaselectronicas?IDR $=3 \% 20 \& I D N=184 \& I D A=15973$

Stanford Encyclopedia of Philosophy. (2017, mayo 31). Contemporary approaches to the social contract. Recuperado de https://plato.stanford.edu/entries/contractarianismcontemporary/\#reduct

Steiner, C. y Fuchs, M.-C. (Eds.) (2019). Convención American sobre Derechos Humanos: comentario. (2. ${ }^{\text {a }}$ ed.). Bogotá, Colombia: Konrad Adenauer Stiftung.

Streb, J. (1998). El significado de racionalidad en economía. Recuperado de https://ucema.edu.ar/publicaciones/download/documentos/139.pdf 
204 | ¿La delegación permanente de funciones jurisdiccionales a las superintendencias colombianas vulnera los derechos humanos?

Tovar Reyes, S. L. (2014). Función jurisdiccional de la Superintendencia Nacional de Salud. Criterio Jurídico, 13(1). Recuperado de https://revistas.javerianacali.edu.co/ index.php/criteriojuridico/article/view/972

Troper, M. (1999). La máquina y la norma: dos modelos de Constitución. DOXA, 22, 330347. Recuperado de http://www.cervantesvirtual.com/research/la-maquina-y-lanorma-dos-modelos-de-constitucion/f3116e86-7d23-40da-97ba-3e41898b4d42. pdf

Vanegas Herrera, R. y Barrera Botero, J. (2012). La jurisdicción mercantil, una alternativa al conflicto judicial y social en Colombia (Tesis de grado, Universidad Pontificia Bolivariana, Medellín, Colombia). Recuperado de https://repository.upb.edu.co/handle/20.500.11912/110

Vesga, I. E. (2019, octubre 12). La pesadilla de Tocqueville. La República. Recuperado de https://www.asuntoslegales.com.co/analisis/ines-elvira-vesga-2752878/la-pesadiIla-de-tocqueville-2920541

Weber, M. (2004). Economía y sociedad. Ciudad de México, México: Fondo de Cultura Económica. 